\title{
Fuerzas centrífugas y centrípetas en el Pacífico Sur de Costa Rica: los impactos de la expansión agroindustrial
}

\author{
Centrifugal and centripetal forces in the South Pacific territory \\ of Costa Rica: the impacts of agroindustrial expansion
}

\author{
Yazmín León Alfaro ${ }^{1^{*}}$ (1) \\ Frank González Brenes ${ }^{2}$ (1) \\ Nieves López Estébanez $z^{3}$ (1)
}

\section{Resumen}

Dentro del contexto Centroamericano, la región Pacífico Sur de Costa Rica destaca por su riqueza cultural y biológica; pero también por la manifestación de los impactos negativos de la expansión agroindustrial. Históricamente, esta región se ha visto marginada respecto al núcleo geo-histórico del país, y se ha caracterizado por el rezago socioeconómico y deterioro ambiental. En este sentido, en la presente investigación interesa abordar el caso de la región del Pacífico Sur como una región periférica y transfronteriza, que evidencia el impacto que han tenido las políticas y estrategias del Estado costarricense para el desarrollo nacional, en la configuración de los sistemas productivos regionales. A partir de un trabajo de campo que comprendió entrevistas en profundidad y observación directa, más la consulta de fuentes bibliográficas, estadísticas de agroproducción e indicadores socioeconómicos diversos, se analiza la incidencia de los agromodelos vigentes en la región. Como resultado, se sintetizan las principales fuerzas centrífugas y centrípetas que se asocian al rezago socioeconómico y a los desequilibrios territoriales manifestados en el territorio. Finalmente, se proponen posibles rutas de acción para superar los desequilibrios imperantes, destacando la agricultura familiar como un modelo productivo más sostenible y acorde a las características socio ecológicas regionales.

Palabras clave: Agromodelos; periferias; Pacífico Sur; Costa Rica.
Abstract
The South Pacific region of Costa Rica stands out for its cultural and biological richness in Central America. By contrast, this area is remarkable for the negative impacts of agroindustrial development. Throughout history this region has been marginalized with respect the geo-historical centre of the country. Socio-economic backwardness and environmental degradation are some of the region's main features. The research analyses the South Pacific region as a peripheral and cross-border region. This area is included within the policies and strategies of the Costa Rican state for national development and the configuration of regional production systems. The management and consequences of the current agri-models in the region are analysed by different methods. Fieldwork method includes in-depth interviews and direct observation. In addition, we have used bibliographic sources, statistics of agri-production, and socioeconomic indicators.

\footnotetext{
1 Centro de Investigaciones sobre Diversidad Cultural y Estudios Regionales (CIDICER), Sede de Occidente, Universidad de Costa Rica. (Costa Rica). yazmin.leonalfaro@ucr.ac.cr. * Autora para correspondencia

2 Laboratorio de Ecología Urbana, Universidad Estatal a Distancia (Costa Rica).fgonzalezb@uned.ac.cr

3 Departamento de Geografía, Facultad de Filosofía y Letras, Universidad Autónoma de Madrid (España). nieves.lopez@uam.es 
Information about the main centrifugal and centripetal forces and linkages with the socio-economic deficiencies and the territorial imbalances is summarised. Finally, the work proposes possible courses of action to overcome the prevailing imbalances and encourage a more sustainable production model for family farming and an agro-system better suited to the socio-ecological characteristics of the region.

Keywords: Agri-models; peripheral regions; South Pacific; Costa Rica; Central America.

\section{Introducción}

\subsection{El contexto Centroamericano}

Centroamérica es uno de los hotspots mundiales en biodiversidad, en la que se estima una extensión de la vegetación primaria de $231.000 \mathrm{~km}^{2}$ con un 59,9\% de ese territorio protegido (Myers, Mittermeier, Mittermeier, Da Fonseca y Kent, 2000). Sin embargo, entre 1990 y 2012, la deforestación aumentó un 9\%, evidenciando la necesidad de esfuerzos para conservar este patrimonio natural de enorme interés (Salido, 2015). Uno de los cambios más importantes de los últimos años, concretamente en el ámbito Centroamericano, es la expansión de los cultivos industriales (Quesada, 2007; Valverde, Rodríguez y Mora, 2018); siendo para 2017 los más importantes por valor de exportación el café (US\$2.928 millones), la caña de azúcar (US\$722 millones), y la palma aceitera (US\$191 millones). Es preocupante la expansión de los cultivos comerciales en toda la región, principalmente el banano (US\$2.594 millones) (Central America Data, 2019); seguido de la piña, producto del que sólo Costa Rica exportó en 2019 US\$930 millones (CANAPEP, s.f.).

En contraste con los grandes cultivos comerciales como la piña, el banano y la palma, esta región es una de las más importantes en el desarrollo y mantenimiento de la agricultura familiar (Gómez, Le Cop y Samper, 2014). Según el informe de CEPAL/FAO/IICA (2013) la agricultura familiar en América Latina y el Caribe alcanzan cerca de 17 millones de unidades productivas e incluye a 60 millones de personas, siendo este sistema cercano al 75\% del total agrícola. Estas cifras resultan aún más interesantes para el área de Centroamérica y México, donde el porcentaje de unidades familiares en proporción al número total de establecimientos es del 78,6\% siendo el número de unidades familiares casi de 6 millones. Costa Rica es el tercer país, después de México y Guatemala en número de personas que mantienen este sistema (79.000) (Schneider, 2016). Estas cifras ponen de manifiesto el interés especial que tiene este tipo de agricultura, aunque constituye un grupo muy heterogéneo en América Latina y El Caribe, que en términos generales posee poca tierra y los más bajos ingresos en el ámbito laboral rural (Comisión Económica para América Latina y el Caribe [CEPAL], 2019). Industrial o familiar, la frontera agrícola en Centroamérica sigue siendo muy activa, experimentando un incremento de 2,5\% de la producción las dos últimas décadas (OECD-FAO, 2019). Resulta particularmente preocupante el caso del avance de la agroindustria de monocultivos, dado que los frentes colonizadores están amenazando los Espacios Naturales Protegidos (ENP) y ecosistemas boscosos remanentes (Shaver et al., 2015). Esta situación es paradójica en una región con tanta biodiversidad y recursos naturales, pues las prácticas poco sostenibles de aprovechamiento de recursos están erosionando su patrimonio natural (Algeet-Abarquero, Marchamalo, Bonatti, Fernández-Moya y Moussa, 2015; International Union for Conservation of Nature [IUCN], 2017).

Por otra parte, estos procesos están llevándose a cabo en regiones periféricas y/o transfronterizas, alejadas de los centros de administración y gestión, en un contexto de escasas infraestructuras terrestres para la movilidad que afecta el acceso y la calidad de los servicios básicos y en general las condiciones socioeconómicas de la población (Bonilla, 2008; Medina, 2004). La deficiente comunicación terrestre con las capitales y centros administrativos (Durango et al., 2019), ha favorecido un deficiente control nacional en la explotación de recursos naturales, mientras grandes multinacionales agroindustriales se instalan en las áreas periféricas, ocupando el lugar de dinamizadores de la economía local, dadas las condiciones de pobreza y desempleo de estas regiones (Rodríguez, 2014). La escasa preocupación por el establecimiento de políticas integrales de desarrollo rural en estas regiones periféricas y/o transfronterizas de los países del Istmo Centroamericano ha abierto la puerta a una serie de fuerzas centrífugas y centrípetas que actúan en las regiones rurales de esta área, generando intensas incertidumbres socioambientales (Consejo Agropecuario Centroamericano [CAC], 2010; Durango et al., 2019).

En Costa Rica, al agotarse la frontera agraria, inició un proceso de transición hacia un nuevo modelo agrícola (Bartels y Araya, 2010; Botella, 2010), donde la inversión transnacional asumió un rol protagonista en el desarrollo territorial, dada la carencia de un plan de desarrollo claro por parte del Estado, en 
particular para las regiones periféricas y rurales, como la región del Pacífico Sur (Amador et al., 2011; Carmack, 1994).

La evolución de los modelos de desarrollo en el país (Figura 1) ha tendido hacia una "economía hacia afuera", regida por las reglas del comercio internacional en el ámbito agropecuario. Ello, ha implicado que las políticas internas concuerden con las regulaciones e intereses internacionales (Botella, 2010; GFA Consulting Group S. A., 2010). Bajo ese modelo, el país buscó posicionarse en la economía mundial por medio de cultivos como el café (Fernández, 2003; Hall, 1976; Vargas y Mora, 2017) y más adelante con el banano y la expansión ganadera (Arroyo y León, 2017; Molina, 2005). La dependencia excesiva de unos pocos cultivos de exportación sometió a la economía nacional a una gran inestabilidad, determinada principalmente por las fluctuaciones de los precios internacionales del café (Fernández Arias, 2003; Vargas, 2015) y se produjeron efectos ambientales adversos, convirtiendo una gran cantidad de tierras agrícolas a pastizales y provocando una disminución de la cobertura boscosa de forma muy significativa (De Camino, Villalobos y Morales, 2015; Sánchez-Azofeifa, 2015).

Figura 1. Estrategias y modelos de desarrollo en Costa Rica y su evolución temporal

\begin{tabular}{|c|c|c|c|c|c|c|c|c|c|c|}
\hline & \multicolumn{7}{|c|}{ Economía rural y agrícola - desarrollo centrípeto } & \multicolumn{3}{|c|}{ Economía global - desarrollo centrífugo } \\
\hline CRONOLOGIA & \multicolumn{3}{|c|}{$\begin{array}{l}\text { Ocupación española- } \\
\text { independencia }\end{array}$} & \multicolumn{3}{|c|}{ 1840-II Guerra Mundial } & $1950-1980$ & \multicolumn{3}{|l|}{$1980-2000$} \\
\hline $\begin{array}{l}\text { SISTEMA } \\
\text { POLITICO/ } \\
\text { PAPELDEL }\end{array}$ & $\begin{array}{l}\text { Corona } \\
\text { española }\end{array}$ & \multicolumn{2}{|c|}{$\begin{array}{l}\text { Estado } \\
\text { liberal }\end{array}$} & \multicolumn{2}{|c|}{$\begin{array}{l}\text { Transición del } \\
\text { liberalismo al Estado } \\
\text { proteccionista }\end{array}$} & \multicolumn{2}{|c|}{$\begin{array}{l}\text { Transición del } \\
\text { proteccionismo al Estado } \\
\text { empresario }\end{array}$} & \multicolumn{3}{|c|}{$\begin{array}{l}\text { Transición del Estado empresario al Estado } \\
\text { neoliberal y profundización del modelo }\end{array}$} \\
\hline $\begin{array}{c}\text { MODELOI } \\
\text { ESTRATEGIA } \\
\text { DEDESARROLLO }\end{array}$ & \multicolumn{2}{|c|}{$\begin{array}{l}\text { Economía rural } \\
\text { colonial precapitalista }\end{array}$} & $\Rightarrow$ & \multicolumn{2}{|c|}{$\begin{array}{c}\text { Economia rural } \\
\text { capitalista basada en } \\
\text { modelo Agroexportador }\end{array}$} & \multicolumn{2}{|r|}{$\begin{array}{c}\text { Desarrollista e } \\
\text { industrialización } \\
\text { sustitutiva }\end{array}$} & $\begin{array}{c}\text { Estrategia de } \\
\text { desarrollo basada } \\
\text { En la ideología } \\
\text { Neoliberal }\end{array}$ & $\Rightarrow$ & $\begin{array}{c}\text { Profundizacion } \\
\text { de la estrategia } \\
\text { Neoliberal }\end{array}$ \\
\hline & \multicolumn{2}{|l|}{$\downarrow$} & & $\downarrow$ & & & $\downarrow$ & $\downarrow$ & & $\downarrow$ \\
\hline & \multirow{2}{*}{\multicolumn{2}{|c|}{$\begin{array}{l}\text { - Agricultura semi- } \\
\text { especializada } \\
\text { regionalmente } \\
\text { - Agricultura de } \\
\text { subsistencia, } \\
\text { ganadería y } \\
\text { agricultura comercial } \\
\text { de caña de azúcar y } \\
\text { tabaco } \\
\text { - El café: Inicio de la } \\
\text { vinculación al } \\
\text { mercado } \\
\text { internacional }\end{array}$}} & \multirow{2}{*}{\multicolumn{2}{|c|}{$\begin{array}{l}\text { - Economia basada en } \\
\text { la exportación del } \\
\text { café y de banano } \\
\text { - Desplazamiento de la } \\
\text { agricultura de } \\
\text { subsistencia y } \\
\text { reducción de la } \\
\text { diversidad productiva } \\
\text { - Clase cafetalera } \\
\text { agroexportadora y } \\
\text { comerciantes son los } \\
\text { grupos favorecidos }\end{array}$}} & \multirow{2}{*}{\multicolumn{3}{|c|}{$\begin{array}{l}\text { - Basado en el modelo desarrollista } \\
\text { de la CEPAL } \\
\text { - Incentivos para la diversificación } \\
\text { productiva (caña de azúcar, arroz, } \\
\text { ganadería y banano) } \\
\text { - Incorporación del sector industrial } \\
\text { - Diversificación para consumo } \\
\text { interno e incentivo a la exportación. } \\
\text { - Auge de ganadería para } \\
\text { exportación que conlleva } \\
\text { degradación ambiental } \\
\text { - Gran dependencia de agricultores a } \\
\text { las ayudas estatales }\end{array}$}} & \multirow{2}{*}{\multicolumn{2}{|c|}{$\begin{array}{l}\text { - Estrategia promovida por la } \\
\text { Agencia Estadounidense para el } \\
\text { Desarrollo Internacional } \\
\text { (USAID) } \\
\text { - Promoción del desarrollo agrario } \\
\text { mediante inversión extranjera y } \\
\text { el incentivo a exportaciones no } \\
\text { tradicionales } \\
\text { - Crecimiento y auge de } \\
\text { monocultivos de piña y palma } \\
\text { para exportación } \\
\text { Desestimulación de producción } \\
\text { de granos básicos, los que } \\
\text { deben importarse cada vez más }\end{array}$}} & \multirow{2}{*}{$\begin{array}{l}\text { - Reducción del papel del } \\
\text { Estado y aumento de la } \\
\text { transnacionalización del } \\
\text { capital } \\
\text { - Dependencia de créditos de } \\
\text { entes financieros } \\
\text { internacionales } \\
\text { - Apertura comercial mediante } \\
\text { tratados de libre comercio } \\
\text { - Graves externalidades } \\
\text { ambientales y sociales } \\
\text { - Se privilegia a los grandes } \\
\text { productores, agronegocios y } \\
\text { transnacionales }\end{array}$} \\
\hline $\begin{array}{l}\text { PRINCIPALES } \\
\text { CARACTERISTICAS }\end{array}$ & & & & & & & & & & \\
\hline
\end{tabular}

Fuente: Basado en Vargas (2015); Molina (2005). Elaboración propia

Ante esta situación, el Estado procuró promover el desarrollo endógeno mediante una mayor diversificación productiva interna y la exportación (Bartels y Araya, 2010; León, 2012), ampliando la estructura económica a través de la industrialización, el desarrollo de infraestructuras, la nacionalización bancaria, la educación, la salud, los créditos, etc. (Arias y Muñoz, 2007; Bartels y Araya, 2010; Botella, 2010; González, 1993; Vargas, 2015). Todo esto en el marco de la estrategia desarrollista y de sustitución de importaciones de la región, y con la intención de integrar el Mercado Común Centroamericano (Abarca y Ramírez, 2016; Vargas, 2015). La integración Centroamericana no prosperó y se generó una alta dependencia de los pequeños agricultores a las ayudas del Estado, una baja vinculación con la agroindustria (Castillo, 2006; Sáenz, 2002) y el aumento de la importación de insumos agrícolas.

En la década de 1980, Centroamérica cae en una severa crisis fiscal y de estancamiento económico generalizado (Arias y Muñoz, 2007; Sáenz, 2002), ante la que el Fondo Monetario Internacional (FMI) y el Banco Mundial plantean una serie de medidas reestructurantes (Programas de Ajuste Estructural, Agencia Estadounidense para el Desarrollo Internacional) (Arias y Muñoz, 2007; González, 1993), atrayendo capital extranjero y la transnacionalización de la producción agraria. Entran ahora en escena productos nuevos como los cítricos, la piña y la palma aceitera (Botella, 2010) privilegiando la agroindustria, en buena parte financiada por capital extranjero (Arias y Muñoz, 2007). Bajo la ideología neoliberal, a partir de 1980, la economía nacional se ve cada vez más sujeta a las leyes del mercado internacional y de los 
tratados de libre comercio. Además, se genera una expansión creciente de plantaciones de piña y palma aceitera, altamente dependientes de pesticidas, y con externalidades ambientales sumamente negativas (Echeverría-Sáenz et al., 2012; Galt, 2020; Lawrence, 2010).

\subsection{Modelos de desarrollo y su impacto en la agroproducción en el Pacífico Sur}

Las estadísticas productivas evidencian los cambios ocurridos en la agricultura y unidades productivas, en relación con los sucesivos modelos y estrategias de desarrollo en el país, particularmente en la región del Pacífico Sur. Son los censos agropecuarios nacionales de 1973, 1984 y 2014 del Instituto Nacional de Estadística y Censos [INEC] los que permiten identificar el peso creciente que tienen los monocultivos de exportación de piña y palma aceitera (Tabla 1).

Tabla 1. Agroproductividad nacional y del Pacífico Sur, según censos agropecuarios nacionales de 1973, 1984 y 2014

\begin{tabular}{|l|c|c|c|c|c|c|c|c|c|c|}
\hline Período censal & \multicolumn{3}{|c|}{1973} & \multicolumn{3}{|c|}{1984} & \multicolumn{3}{c|}{2014} \\
\hline $\begin{array}{l}\text { Producción } \\
\text { agrícola (Ha) }\end{array}$ & $\begin{array}{c}\text { Nacional } \\
(\mathrm{Ha})\end{array}$ & $\begin{array}{c}\text { Pacifico } \\
\text { Sur (Ha) }\end{array}$ & $\begin{array}{c}\text { Tasa de } \\
\text { aporte }\end{array}$ & $\begin{array}{c}\text { Nacional } \\
(\mathrm{Ha})\end{array}$ & $\begin{array}{c}\text { Pacifico } \\
\text { Sur (Ha) }\end{array}$ & $\begin{array}{c}\text { Tasa de } \\
\text { aporte }\end{array}$ & $\begin{array}{c}\text { Nacional } \\
\text { (Ha) }\end{array}$ & $\begin{array}{c}\text { Pacifico } \\
\text { Sur (Ha) }\end{array}$ & $\begin{array}{c}\text { Tasa de } \\
\text { aporte }\end{array}$ \\
\hline Palma aceitera & $5.060,0$ & $4.127,0$ & $81,6 \%$ & $16.830,0$ & $8.021,0$ & $47,7 \%$ & $66.420,0$ & $18.645,0$ & $28,07 \%$ \\
\hline Piña & 736,0 & 259,0 & $35,2 \%$ & $2.474,0$ & $1.106,0$ & $44,7 \%$ & $37.659,6$ & $7.144,0$ & $18,97 \%$ \\
\hline Banano & $36.153,8$ & $10.051,9$ & $27,8 \%$ & $32.319,2$ & $5.061,0$ & $15,7 \%$ & $51.758,0$ & $1.268,7$ & $2,45 \%$ \\
\hline Café & $83.405,9$ & $13.718,1$ & $16,4 \%$ & $89.880,4$ & $14.567,1$ & $16,2 \%$ & $84.133,1$ & $22.730,0$ & $27,02 \%$ \\
\hline Caña de azúcar & $38.760,4$ & $1.630,6$ & $4,2 \%$ & $47.280,0$ & $2.253,0$ & $4,8 \%$ & $65.061,9$ & $4.570,0$ & $7,02 \%$ \\
\hline Arroz & $65.456,0$ & $17.134,8$ & $26,2 \%$ & $86.439,0$ & $11.892,0$ & $13,8 \%$ & $58.539,7$ & $13.427,8$ & $22,94 \%$ \\
\hline Producción pecuaria (cabezas de ganado) \\
\hline $\begin{array}{l}\text { Ganadería de } \\
\text { Leche }\end{array}$ & $130.930,0$ & n.d. & n.d. & $383.188,0$ & $120.089,0$ & $31,3 \%$ & $327.130,0$ & $14.810,0$ & $4,53 \%$ \\
\hline $\begin{array}{l}\text { Carne/leche y } \\
\text { carne }\end{array}$ & $1.693 .942,0$ & n.d. & n.d. & $2.035 .535,0$ & $260.077,0$ & $12,8 \%$ & $1.272 .852,0$ & $139.017,0$ & $10,92 \%$ \\
\hline Porcino & $215.972,0$ & $41.166,0$ & $19,1 \%$ & $282.527,0$ & $43.741,0$ & $15,5 \%$ & $435.243,0$ & $52.574,0$ & $12,08 \%$ \\
\hline
\end{tabular}

n.d.= no disponible

Fuente: Arroyo y León (2017); Instituto Costarricense del Café (ICAFE) (2019). Elaboración propia

El cultivo de palma aceitera tuvo sus inicios en el Pacífico Sur en 1964, como respuesta a la crisis del banano en los cantones de Golfito y Corredores (Ministerio de Agricultura y Ganadería [MAG], 2007). En 1973, a escala nacional, se cultivaban 5.060 ha y aumentó a 16.830 ha en 1984, y a 18.645 ha en el 2014. Sin embargo, en 2018 la región Sur aumentó el área cultivada a 48.880 ha, el equivalente al 71,7\% del total del área cultivada a escala nacional. Corredores, Osa y Golfito, en el área baja, presentaban las mayores extensiones de área cultivada de palma aceitera: 26.280 ha, 11.822 ha y 8.100 ha, respectivamente. En el sector alto, Buenos Aires y Coto Brus, tenían las menores áreas de cultivo: 2.378 ha y 300 ha, respectivamente (Arroyo y León, 2017). Comparativamente, entre 1973 y el 2014 el área cultivada de palma aceitera en la región casi se cuadruplicó (Tabla 1). De forma similar sucedió entre el 2014 y el 2018. Tal es el auge de este cultivo que, de enero a noviembre de 2019, Costa Rica fue el segundo exportador de aceite de palma en Centroamérica (US\$58 millones) (Central America Data, 2020). En cuanto a la producción de piña, los datos aportados por la Cámara Nacional de Productores y Exportadores de Piña (CANAPEP), indican una extensión de 44.500 ha cultivadas con piña en el país, de las que un 19\% están en el Pacífico Sur. Sin embargo, los datos de extensión del cultivo a escala nacional son inferiores a los registrados por el Monitoreo de Cambio de Uso en Paisajes Productivos (MOCCUP) del PRIAS (Programa de Investigaciones Aerotransportadas y Sensores Remotos e in situ [PRIAS], 2019a), quienes estimaron 57.327 ha sembradas con piña en el período 2015-2016 y el registro correspondiente al año 2017 asciende a $66.266 \mathrm{ha}$, con lo que la cobertura de piña habría aumentado 15,7\% en tan solo un año. Los datos de 2018 del MOCCUP indican un total de 65.670,68 ha cultivadas de piña en todo el país, lo que representa 1,29\% del territorio nacional. En 2018 la región Pacífico Sur ocupaba el tercer lugar en producción, con el 13\% del total del país.

Por otro lado, en cuanto a granos básicos entre 2008 y 2015 Leiva y Vargas (2017) determinaron un aumento del 4,71\% en el área cultivada de frijol; en contraposición, una disminución del -2,27\% y 
-15,63\% para los cultivos de arroz y maíz, respectivamente y cuya producción corresponde, principalmente a explotaciones en manos de pequeños productores. Respecto a la producción pecuaria, las tasas de aporte para ganadería de leche, carne y leche y porcina evidencian, en general, una disminución, al comparar los datos agropecuarios de los años 1984 y 2014 (Tabla 1).

\subsection{Desigualdades y contrastes socioambientales en el territorio}

El Pacífico Sur presenta fuertes desequilibrios en comparación con otras regiones del país (Bartels y Araya, 2010). Las desigualdades se relacionan, en buena parte, con las diferencias culturales y étnicas que, junto al aislamiento, generan condiciones de marginalidad (Solórzano, 1992). La región presenta las mayores desventajas en cuanto a condiciones socioeconómicas, lo cual motiva a muchos de sus habitantes a emigrar, principalmente hacia la región Central o a Estados Unidos (Comité Sectorial Regional Agropecuario [CSRA], 2007; Morales Gamboa et al., 2011). Los datos de INEC (2012) (Tabla 2), muestran que el indicador de población de "pobreza extrema" regional duplica el valor nacional, y triplica el valor para la región Central. Además, la cantidad de "hogares pobres" de la región duplica el valor para la región Central, y supera en 14 puntos porcentuales el valor nacional.

Tabla 2. Situación de pobreza regional comparada (\%)

\begin{tabular}{|l|c|c|c|}
\hline \multicolumn{1}{|c|}{ Indicadores } & Costa Rica & Región Central & Región Pacífico Sur \\
\hline Población pobre & 23,60 & 18,60 & 38,60 \\
\hline Población en pobreza extrema & 7,20 & 4,90 & 14,60 \\
\hline Hogares pobres & 20,60 & 16,30 & 34,60 \\
\hline Hogares en pobreza extrema & 6,30 & 4,30 & 12,90 \\
\hline
\end{tabular}

Fuente: INEC. Encuesta Nacional de Hogares (2012). Elaboración propia

Esta situación de pobreza ofrece las condiciones idóneas para que las redes del narcotráfico establezcan sus nodos en la región (Wrathall et al., 2020). Si bien es cierto que el problema es generalizado en la región, los territorios indígenas y los grandes espacios protegidos, como los Parques Nacionales de Corcovado y La Amistad, y el humedal Térraba-Sierpe, que presentan condiciones topográficas complejas y que dificultan una vigilancia efectiva, se convierten en sitios para ocultar y transportar droga proveniente, principalmente, de Colombia. Corrales (2019), señala que el 25,5\% de las plantaciones de marihuana erradicadas entre 2007 y 2018 en Costa Rica estaban ubicadas en el Pacífico Sur, siendo el Parque Internacional de la Amistad (PILA) el ENP con el mayor número de plantaciones a escala nacional (81\%). Señala ese mismo autor que solamente en el territorio indígena de Rey-Curré se localizó el 13\% del total de marihuana erradicada en territorios indígenas a escala nacional.

En congruencia con los datos anteriores, y según Ulate, Mayorga y Alfaro (2017), el Índice de Competitividad Cantonal (ICC) situaba a los municipios de la región en las categorías Muy baja o Baja. Buenos Aires ocupa el penúltimo lugar, de un total de 81 municipios, habiéndose mantenido en la categoría Muy baja de competitividad entre los años 2006 y 2016. Por su parte, Coto Brus, Corredores y Golfito presentan el mismo comportamiento que Buenos Aires, localizándose en la categoría Muy baja en estos dos años y ocupando los puestos 76, 74 y 71 del ICC, respectivamente. El municipio de Pérez Zeledón y el de Osa presentan cierta mejoría respecto al resto de la región, sin embargo, se encuentran en la categoría Baja del ICC, ocupando los lugares 61 y 47 respectivamente.

En contraste con las actividades extractivistas y los impactos socioambientales asociados, el esfuerzo estatal y privado para la conservación de los recursos naturales es considerable, si se tiene en cuenta que el país pasó de tener una cobertura forestal del 40,8\% en 1986, a 51,4\% en el 2010, como resultado de sus políticas conservacionistas (Sánchez-Azofeifa, 2015; Sánchez-Azofeifa et al., 2002). Tal esfuerzo es evidente en la región Sur, donde existe una considerable biodiversidad, resguardada mediante numerosas figuras de protección (Tabla 3), que cubren un 23,4\% del territorio analizado con más de 423 mil ha. Se han identificado 28 ENP, destacando la presencia de 6 Parques Nacionales, máxima categoría de protección en el país, que cubren un total de 104.402,97 ha y entre los que destaca Corcovado, Marino Ballena, Chirripó, y La Amistad. Entre los humedales sobresale Térraba-Sierpe, que ha recibido la denominación 
de Sitio RAMSAR como humedal de importancia internacional (Ministerio de Planificación Nacional y Política Económica [MIDEPLAN], 2014; Sistema Nacional de Áreas de Conservación [SINAC], s.f.). Desde el punto de vista del tipo de gestión de las áreas protegidas presentes en el área, la mayor parte tiene una gestión estatal (223.008 ha), pero destaca la presencia de la gestión mixta (público-privada) en casi 199.000 ha. Este último tipo de gestión se desarrolla en los Refugios Nacionales de Vida Silvestre. Por último, la gestión privada es residual en el área con apenas 1.680 ha y utilizada en tres Refugio Nacional de Vida Silvestre (Tabla 3).

Tabla 3. Espacios Naturales Protegidos de la región Pacífico Sur

\begin{tabular}{|c|c|c|c|c|c|}
\hline \multirow{2}{*}{$\begin{array}{l}\text { Categoría } \\
\text { de manejo }\end{array}$} & \multirow{2}{*}{ Nombre del ENP } & \multirow{2}{*}{$\mathrm{Ha}$} & \multicolumn{3}{|c|}{ Gestión } \\
\hline & & & Estatal & Privada & Mixta \\
\hline \multirow{2}{*}{$\begin{array}{l}\text { Corredor } \\
\text { Biológico }\end{array}$} & $\begin{array}{l}\text { Perteneciente a Sistema Nacional de } \\
\text { Conservación- Área de Conservación } \\
\text { La Amistad Pacífico (SINAC-ACLAP) }\end{array}$ & $114.930,54$ & & & $\bullet$ \\
\hline & $\begin{array}{l}\text { Perteneciente a Sistema Nacional de } \\
\text { Conservación - Área de Conservación } \\
\text { Osa (SINAC-ACOSA) }\end{array}$ & $49.471,53$ & & & $\bullet$ \\
\hline \multirow{3}{*}{ Humedal } & San Vito & 43,72 & $\bullet$ & & \\
\hline & Lacustrino Laguna del Paraguas & 49,58 & $\bullet$ & & \\
\hline & Térraba-Sierpe & $32.325,0$ & $\bullet$ & & \\
\hline \multirow{6}{*}{$\begin{array}{l}\text { Parque } \\
\text { Nacional }\end{array}$} & Chirripó & $17.160,7$ & $\bullet$ & & \\
\hline & Corcovado & $42.226,3$ & $\bullet$ & & \\
\hline & Marino Ballena & $5.546,01$ & $\bullet$ & & \\
\hline & Piedras Blancas & $14.133,4$ & $\bullet$ & & \\
\hline & La Amistad & 25.264 & • & & \\
\hline & Tapantí & 72,56 & $\bullet$ & & \\
\hline \multirow{13}{*}{$\begin{array}{l}\text { Refugio } \\
\text { Nacional } \\
\text { de Vida } \\
\text { Silvestre }\end{array}$} & Carate & 140,37 & & & $\bullet$ \\
\hline & Finca Barú del Pacifico & 326,62 & & & $\bullet$ \\
\hline & Golfito & $2.868,47$ & & & $\bullet$ \\
\hline & Longo Mai & 928,43 & & $\bullet$ & \\
\hline & Montana de El Tigre & 282,81 & & $\bullet$ & \\
\hline & Osa & $1.749,44$ & & & $\bullet$ \\
\hline & Pejeperro & $2.748,01$ & & & $\bullet$ \\
\hline & Preciosa Platanares & 263,23 & & & $\cdot$ \\
\hline & Punta Río Claro & 319,73 & & & $\bullet$ \\
\hline & Quillotro & 66,49 & & & $\cdot$ \\
\hline & Rancho La Merced & 410,15 & & & - \\
\hline & Río General & 470,65 & & $\bullet$ & \\
\hline & Saimiri & 106,9 & & & - \\
\hline $\begin{array}{l}\text { Reserva } \\
\text { Biológica } \\
\end{array}$ & Isla del Caño & $5.527,42$ & $\bullet$ & & \\
\hline \multirow{2}{*}{$\begin{array}{l}\text { Reserva } \\
\text { Forestal }\end{array}$} & Golfo Dulce & $60.678,6$ & $\bullet$ & & \\
\hline & Los Santos & $24.951,4$ & & & $\bullet$ \\
\hline $\begin{array}{l}\text { Zona } \\
\text { Protectora }\end{array}$ & Las Tablas & $19.981,1$ & • & & \\
\hline \multicolumn{2}{|l|}{ Total (Ha) } & $423.043,2$ & $223.008,39$ & $1.681,89$ & $198.352,88$ \\
\hline
\end{tabular}

Fuente: SINAC-ACLAP y SINAC-ACOSA (2020). Elaboración propia 
El Pacífico Sur de Costa Rica, es una región periférica y transfronteriza que evidencia el impacto que han tenido las políticas y estrategias del Estado costarricense para el desarrollo nacional, en la configuración de los sistemas productivos regionales y en los cambios socioambientales evidenciados en este territorio (Harvey, Alpízar, Chacón y Madrigal, 2004). Esta investigación trata de resolver los siguientes interrogantes: ¿cómo son los modelos agroproductivos actuales en el Pacífico Sur costarricense? ¿Cuáles son las dinámicas territoriales del agromodelo actual de la región? ¿Cuáles son los puntos débiles y las fortalezas de este sistema? y ¿qué oportunidades pueden ser la base de un desarrollo rural real en el contexto actual?

\section{Metodología}

\section{1. Área de estudio: una periferia en el centro del Istmo}

La región del Pacífico Sur tiene una extensión de 9.528,44 km², que corresponde al 18,6\% del territorio costarricense (Bartels y Araya, 2010) (Figura 2). De acuerdo al último censo de población del año 2011 , en este espacio habitan un total de 328.645 personas, de las cuales el 49,5\% corresponde a hombres y el $50,5 \%$ a mujeres. Esta población equivale a 7,1\% de la población del país. En contraste, la región Central (la más poblada de Costa Rica), contaba en el año 2011 con 2.688.664 habitantes, lo que equivale al 66\% de la población total de Costa Rica en tan solo un 16\% del territorio nacional (MIDEPLAN, 2014). De igual manera, la densidad de población en la región Sur es baja, ya que es de apenas 34,5 Hab/ $\mathrm{km}^{2}$, siendo menor a la media nacional $\left(90 \mathrm{Hab} / \mathrm{km}^{2}\right)$; y en el extremo opuesto en la región Central (315 Hab/ $\mathrm{km}^{2}$ ) (MIDEPLAN, 2014). En términos económicos, el ingreso medio por hogar en 2018 se sitúa en US $\$ 1.164$ mensuales, disminuyendo un 3,3\% respecto al 2017 (INEC, 2018). Todo ello la convierte en la segunda región más pobre del país, con índices de pobreza y pobreza extrema de 29,5\%, y 10,4\% respectivamente (INEC, 2018).

Figura 2. Ámbito de estudio

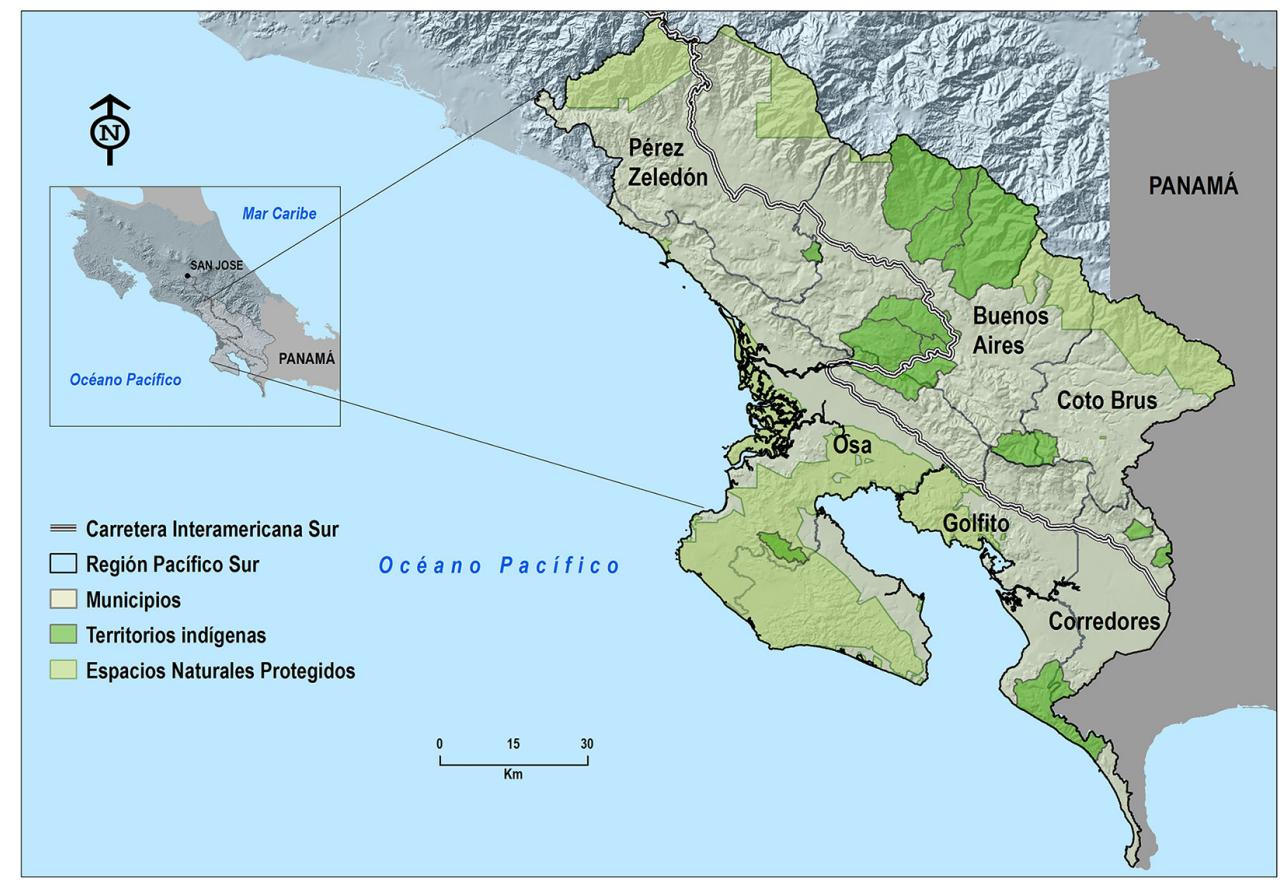

Fuente: Bases cartográficas del Atlas del Instituto Tecnológico de Costa Rica (2014). Elaboración propia

La región tiene una fuerte presencia indígena representada por cinco etnias (Bribris, Borucas, Cabécares, Ngäbes y Térrabas), distribuidas en 12 territorios ${ }^{4}$, con un total de 24.972 personas autodefinidas

\footnotetext{
4 Mediante la ratificación en 1993 del Convenio 169 de la Organización Internacional del Trabajo, Costa Rica adopta la denominación de territorio en términos jurídicos y formales, para designar a las tierras reconocidas por el Estado como lugares de asentamiento de los pueblos indígenas. El territorio contempla el derecho colectivo de los pueblos indígenas, no solo a la posesión de la tierra, sino también a los recursos, a la cultura y a la autodeterminación (Centro de Investigación en Cultura y Desarrollo [CICDE], 2014).
} 
como indígenas, lo que corresponde a un 8,22\% de la población total de la región (Centro Centroamericano de Población, 2011; INEC, 2011). Además, se suma la población no indígena de distintos orígenes, en su mayoría campesinos provenientes de otras regiones del país, de la región de Chiriquí en Panamá, y de Nicaragua (Amador et al., 2011; Arce, 2014; Carmack, 1994); así como población de origen europeo representada, principalmente, por colonos italianos establecidos en San Vito de Coto Brus (Méndez, 2016; SINAC, 2012).

Administrativamente, la región Sur comprende seis municipios: Pérez Zeledón, Buenos Aires, Corredores, Coto Brus, Golfito y Osa (Figura 2). La principal vía que comunica la región con el centro histórico-geográfico del país (Valle Central), es la carretera Interamericana Sur, la cual se extiende por más de 350 km (6 horas 30 minutos de recorrido entre San José y la frontera con Panamá). Debido a las dificultades históricas de conectividad vial, el territorio de esta región fue uno de los últimos en ser colonizado (Amador et al., 2011; Carmack, 1994; Méndez, 2016; Sandner, 1961). El sector alto de la región mantuvo el aislamiento hasta finales del siglo XIX, cuando el gobierno promovió la creación de una ruta de comunicación desde el Valle Central (Carmack, 1994; Méndez, 2016). Posteriormente, inicia un fuerte movimiento de pioneros provenientes de diversas comunidades de la región Central que se establecen en la región del actual municipio de Pérez Zeledón, para desarrollar actividades agrícolas, principalmente la producción de café (Amador et al., 2011; Arce, 2014; Instituto de Desarrollo Rural [INDER], 2014; Méndez, 2016).

A partir de 1950 se inicia en Coto Brus un proceso planificado de colonización a través del cual se consolida el café como la principal actividad económica (Bartels y Araya, 2010; INDER, 2014; Méndez, 2016). En 1970, en Buenos Aires, comienza el monopolio de la esfera económica a través de la actividad agrícola extensiva para la producción de piña a pequeña escala por parte de la compañía Pineapple Development Corporation (PINDECO) (Amador et al., 2011; Bonatti, Borge, Herrera y Paaby, 2005; Carazo y Aravena, 2016; León, González y López, 2019). El territorio bajo que corresponde a Osa, Golfito y Corredores (Figura 2), con una historia más reciente, se pobló y desarrolló con poca planificación por parte del Estado, con asentamientos que surgen a partir de la influencia que ejerció la Compañía Bananera de Costa Rica (CBCR) (Amador et al., 2011; Bonatti et al., 2005). En la segunda mitad del siglo XX se desarrollan actividades de minería y extracción de madera por la empresa Osa Productos Forestales, con importantes impactos ambientales y conflictos sociales (Amador et al., 2011; Calvo, 2012; van den Hombergh, 1999).

\subsection{Métodos}

Para el desarrollo de esta investigación, se recopilaron los datos socioeconómicos referidos al Censo Nacional de Población de 2011, del INEC. Además, se utilizaron las bases cartográficas disponibles en el Atlas de Costa Rica del Instituto Tecnológico de Costa Rica (Ortiz-Malavasi, 2014); las bases cartográficas de cobertura de piña y palma aceitera del Laboratorio del PRÍAS (2019a, 2019b); así como capas de información propias, generadas a partir del trabajo de campo, desarrollado entre julio de 2017 y diciembre de 2019, para la toma de datos y para la realización de entrevistas a gestores de espacios protegidos, líderes locales y otros actores. Con todo ello, se elaboró un sistema de Información Geográfica, que dio lugar a una cartografía sintética de las dinámicas detectadas en el territorio.

Se diseñó una muestra de tipo no probabilística, compuesta por 24 informantes seleccionados bajo el criterio de nivel de experiencia en el tema de investigación (Tabla 4). A cada informante se le aplicó, de forma presencial, una entrevista semiestructurada que fue diseñada para tres grandes grupos de informantes: a) los de incidencia a nivel regional (técnicos, administrativos y académicos vinculados a instituciones y organizaciones no gubernamentales); b) los participantes en las dinámicas de gobernanza y desarrollo local (líderes comunales vinculados con asociaciones, plataformas comunitarias y gobiernos locales indígenas); y c) agroproductores indígenas y campesinos. El propósito de las entrevistas fue indagar de manera directa sobre el criterio técnico, percepción y experiencia vivencial de cada informante, respecto a los siguientes aspectos: las principales problemáticas socioambientales relacionadas con monocultivos extensivos, los aspectos de la organización comunal y sus aportaciones al desarrollo local, la permanencia de los sistemas tradicionales de producción familiar de pequeña escala y las problemáticas asociadas a narcotráfico y delitos contra el medioambiente. La información de carácter cualitativo obtenida mediante las entrevistas fue analizada y contrastada con los datos previamente localizados mediante la revisión bibliográfica de documentos técnicos y de tipo diagnóstico de carácter económico, socioambiental y 
cultural para la región, de tal forma que fuera posible precisar, a una escala más local, los diversos factores que inciden en el modelo de desarrollo regional del Pacífico Sur.

Tabla 4. Tipo de actores entrevistados

\begin{tabular}{|c|c|c|}
\hline Actores & Código & Tipo de Actor \\
\hline \multirow[t]{5}{*}{ Asociaciones y plataformas } & Lc1 & Líder comunal \\
\hline & $L c 2$ & Líder comunal \\
\hline & Lc3 & Líder comunal \\
\hline & Lc4 & Líder comunal \\
\hline & $L c 5$ & Líder comunal \\
\hline \multirow[t]{6}{*}{ Institucional } & Acl & Académico \\
\hline & Aap1 & Administrador de Área protegida \\
\hline & Gap1 & Gerente de Áreas protegidas \\
\hline & Tag1 & Técnico agropecuario \\
\hline & Tal & Técnico ambiental \\
\hline & $\mathrm{Ta} 2$ & Técnico ambiental \\
\hline \multirow[t]{2}{*}{ Organización No Gubernamental } & Oc1 & Conservacionista \\
\hline & Oc2 & Conservacionista \\
\hline \multirow[t]{5}{*}{ Población campesina } & Pag1 & Productor agrícola \\
\hline & Pag2 & Productor agrícola \\
\hline & Pal & Productor Apícola \\
\hline & Pg1 & Productor ganadero \\
\hline & $P g 2$ & Productor ganadero \\
\hline \multirow[t]{5}{*}{ Población indígena } & Agpi & Agroproductores indígenas \\
\hline & Lcil & Líder comunal indígena \\
\hline & Lci2 & Líder comunal indígena \\
\hline & Lci3 & Líder comunal indígena \\
\hline & Lci4 & Líder comunal indígena \\
\hline Regional & Clg1 & Comité local de gestión \\
\hline
\end{tabular}

Código: identificación anónima de los actores.

Elaboración propia

\section{Resultados}

Los datos aportados por diversos actores clave (Tabla 4: Lc1, Lc2, Gap1, Clg1, Oc1, Oc2, Ac1, Ta1, Tg1, Lci2, Lci3) sobre los procesos y dinámicas regionales permite considerarlos, a nivel de municipios, en términos de fortalezas y debilidades que contribuyen a la desigualdad socioambiental en la región (Tabla 5, Figuras 3 y 4 ).

Los procesos y dinámicas considerados como fortalezas están presentes, en general, en los cinco municipios (Tabla 5), destacando las Actividades turísticas sostenibles, las Investigaciones vigentes y la presencia de Organizaciones de base comunal, que se detectan en 5 de los 6 municipios. Sin embargo, parecen ser más propios de las comunidades aledañas a los ENP (Figura 3), que manifiestan una tendencia hacia el desarrollo de modelos productivos basados en el uso sostenible de la biodiversidad. Esto es producto quizá, de un modelo de gobernanza más autónomo, que se nutre de una base asociativa local (Tabla 4: 
Lc1, Lci3), que apuesta por el desarrollo endógeno basado en el capital social y natural. Por otra parte, se han identificado 14 procesos, clasificados como debilidades, de los que 4 de ellos están presentes en todos los municipios analizados (Inadecuado manejo de basura y residuos sólidos, Infraestructuras y equipamientos deficientes, Ocupación ilegal de tierras indígenas y Tráfico de drogas y actividades de crimen organizado). Dichas debilidades regionales parecen estar relacionadas con el modelo económico existente, basado en la agroproducción industrial de monocultivos extensivos (Figura 4). Este modelo, además, aporta poco a la disminución de la pobreza (Tabla 4: Pag1, Pa1, Lci2, Clg1), la cual favorece la utilización de diversas prácticas productivas y económicas que son ambiental y socialmente insostenibles (Rodríguez et al., 2018). A ello se suma la ineficacia de las autoridades locales para atender problemas esenciales del desarrollo regional (Tabla 4: Ac1, Oc1).

Tabla 5. Fortalezas y debilidades en los municipios de la región Pacífico Sur

\begin{tabular}{|c|c|c|c|c|c|c|c|c|}
\hline \multirow{2}{*}{ F/D } & \multirow{2}{*}{ PROCESOS Y DINÁMICAS } & \multicolumn{6}{|c|}{ MUNICIPIOS } & \multirow[b]{2}{*}{$\mathrm{N}^{\mathrm{o}}$} \\
\hline & & $\mathrm{PZ}$ & BA & CB & $\mathrm{O}$ & G & C & \\
\hline \multirow{8}{*}{ Fortalezas } & Producción agraria sostenible $e^{2,8}$ & • & - & • & & & & 3 \\
\hline & Buenas prácticas productivas 2,8 & & & & - & & $\bullet$ & 2 \\
\hline & Iniciativas de conservación y producción sostenible $e^{2,8}$ & & - & • & & & & 2 \\
\hline & Iniciativas conservacionistas ${ }^{2,8}$ & & - & & - & $\bullet$ & $\bullet$ & 4 \\
\hline & Actividades de reforestación ${ }^{2}$ & & - & & - & & & 2 \\
\hline & Actividades turísticas sostenibles ${ }^{2,8}$ & • & • & $\bullet$ & $\bullet$ & • & & 5 \\
\hline & Investigaciones en desarrollo ${ }^{7}$ & • & - & - & $\cdot$ & - & & 5 \\
\hline & Organizaciones de base comunal ${ }^{2,8}$ & $\bullet$ & - & - & $\bullet$ & - & & 5 \\
\hline \multirow{15}{*}{ Debilidades } & Plantaciones de piña ${ }^{1,3,8}$ & $\bullet$ & • & & & & & 2 \\
\hline & Plantaciones de palma aceitera ${ }^{1,3,8}$ & & & & $\bullet$ & $\bullet$ & $\bullet$ & 3 \\
\hline & Ganadería convencional ${ }^{3,8}$ & $\bullet$ & $\bullet$ & $\bullet$ & & - & • & 5 \\
\hline & Producción agraria insostenible ${ }^{3,8}$ & $\bullet$ & - & & $\bullet$ & & & 3 \\
\hline & Deforestación ilegal ${ }^{4}$ & & & & $\bullet$ & - & - & 3 \\
\hline & Incendios forestales recurrentes ${ }^{4,5}$ & $\bullet$ & $\bullet$ & & & & & 2 \\
\hline & Caza ilegal $^{4}$ & & & & $\bullet$ & $\bullet$ & & 2 \\
\hline & Extracción ilegal de oro ${ }^{4}$ & & & & $\bullet$ & $\bullet$ & & 2 \\
\hline & Uso intensivo de pesticidas ${ }^{3}$ & $\bullet$ & - & & $\bullet$ & & & 3 \\
\hline & Contaminación en aguas/Sedimentación ${ }^{3,8}$ & & & & $\bullet$ & & & 1 \\
\hline & Inadecuado manejo de basura y residuos sólidos ${ }^{6,8}$ & $\bullet$ & • & $\bullet$ & $\bullet$ & • & $\bullet$ & 6 \\
\hline & Dificultades en vías de acceso $0^{5,6,8}$ & & & $\bullet$ & $\bullet$ & & - & 3 \\
\hline & Infraestructuras y equipamientos deficientes ${ }^{6,8}$ & $\bullet$ & - & - & $\bullet$ & $\bullet$ & - & 6 \\
\hline & Ocupación ilegal de tierras indígenas ${ }^{4,5}$ & $\bullet$ & • & $\bullet$ & $\bullet$ & $\bullet$ & $\bullet$ & 6 \\
\hline & Tráfico de drogas y actividades de crimen organizado ${ }^{4}$ & $\bullet$ & $\bullet$ & $\bullet$ & $\bullet$ & $\bullet$ & $\bullet$ & 6 \\
\hline
\end{tabular}

PZ: Pérez Zeledón; BA: Buenos Aires; CB: Coto Brus, O: Osa; G: Golfito; C: Corredores

Fuente: ${ }^{1}$ Bases cartográficas del PRIAS (2019a; 2019b); ${ }^{2}$ (Tabla 4: Lc1, Lc2, Lc3, Ta1, Ta2, Oc1, Oc2); ${ }^{3}$ (Tabla 4: Lc2, Lc4, Tag1, Pag1,

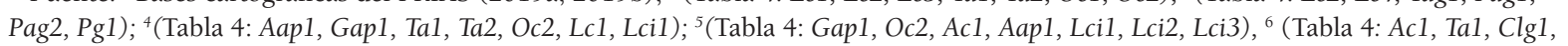
Lc1, Lc4, Lc5, Aap1); 7 SINAC-ACLAP y SINAC-ACOSA (2020); ${ }^{8}$ Comprobación de campo (2020). Elaboración propia

Las iniciativas conservacionistas predominan en los municipios del Sur Bajo, particularmente en la Península de Osa, vinculadas a las actividades de corte ecoturístico, dada la gran riqueza biológica del área (Figura 3). No obstante, en este mismo territorio se producen una serie de delitos que atentan contra los espacios protegidos, como la caza ilegal y la extracción ilegal de oro dentro del Parque Nacional Corcovado (Figura 4). Por otra parte, las prácticas agroganaderas insostenibles se manifiestan tanto en 
los territorios indígenas donde provocan incendios forestales, así como de forma extendida en la cuenca del río Grande de Térraba e inclusive en el Humedal Nacional Térraba-Sierpe, donde se ha identificado contaminación de aguas por uso intensivo de agroquímicos, particularmente asociado a los monocultivos (Tabla 4: Aap1, Gap1, Ta1, Ta2, Oc2, Lc1, Lci1, Lci2) (Figura 4).

Figura 3. Fortalezas en la región Pacífico Sur

(Gris oscuro: Territorios Indígenas; gris claro: Espacios Naturales Protegidos)
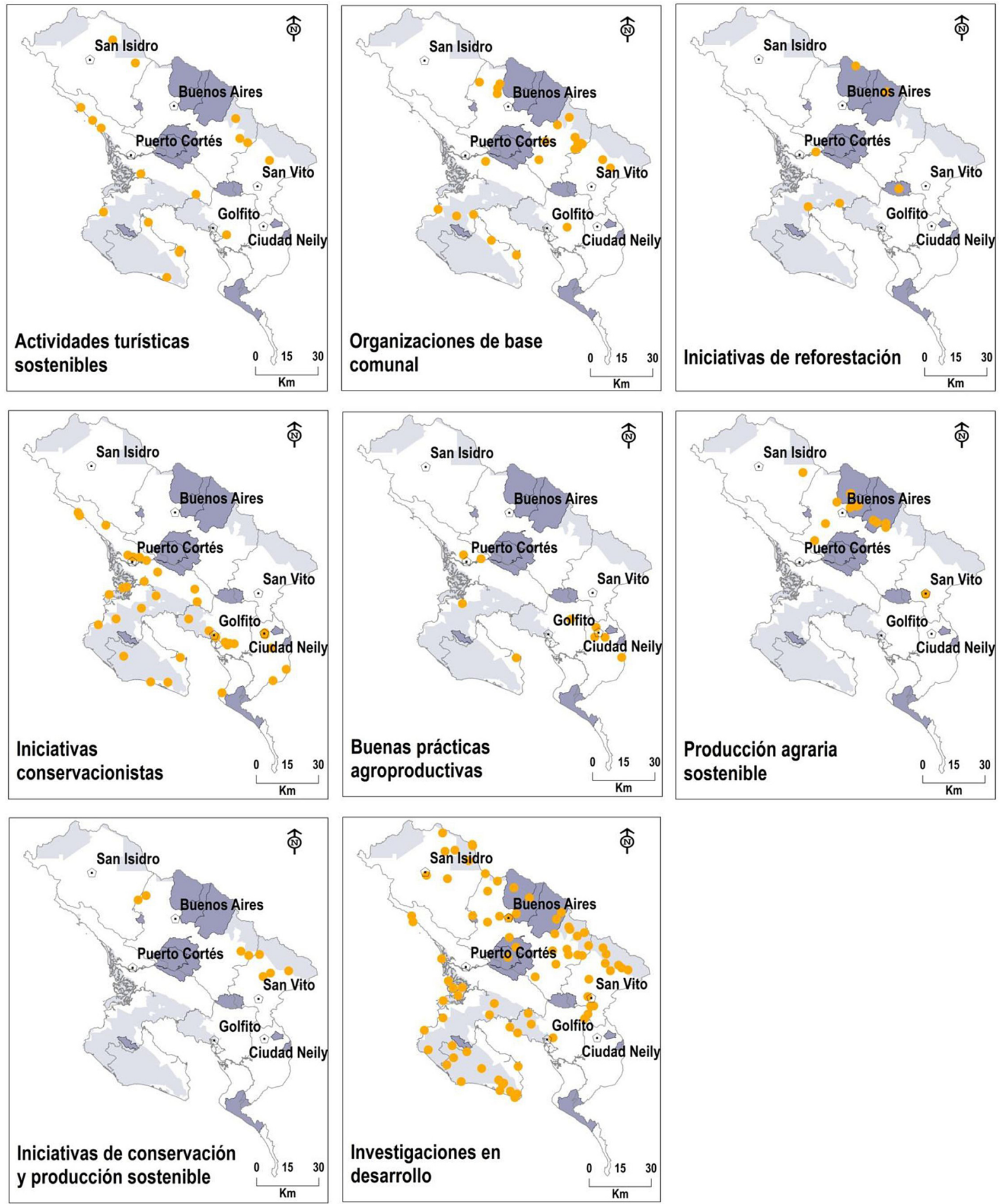

Fuente: Bases cartográficas del Atlas del Instituto Tecnológico de Costa Rica (2014); (Tabla 1: Lc1, Lc2, Lc3, Ta1, Ta2, Oc1, Oc2); SINACACLAP y SINAC-ACOSA (2020); Comprobación de campo (2020). Elaboración propia 
Figura 4. Debilidades en la región Pacífico Sur

(Gris oscuro: Territorios Indígenas; gris claro: Espacios Naturales Protegidos)
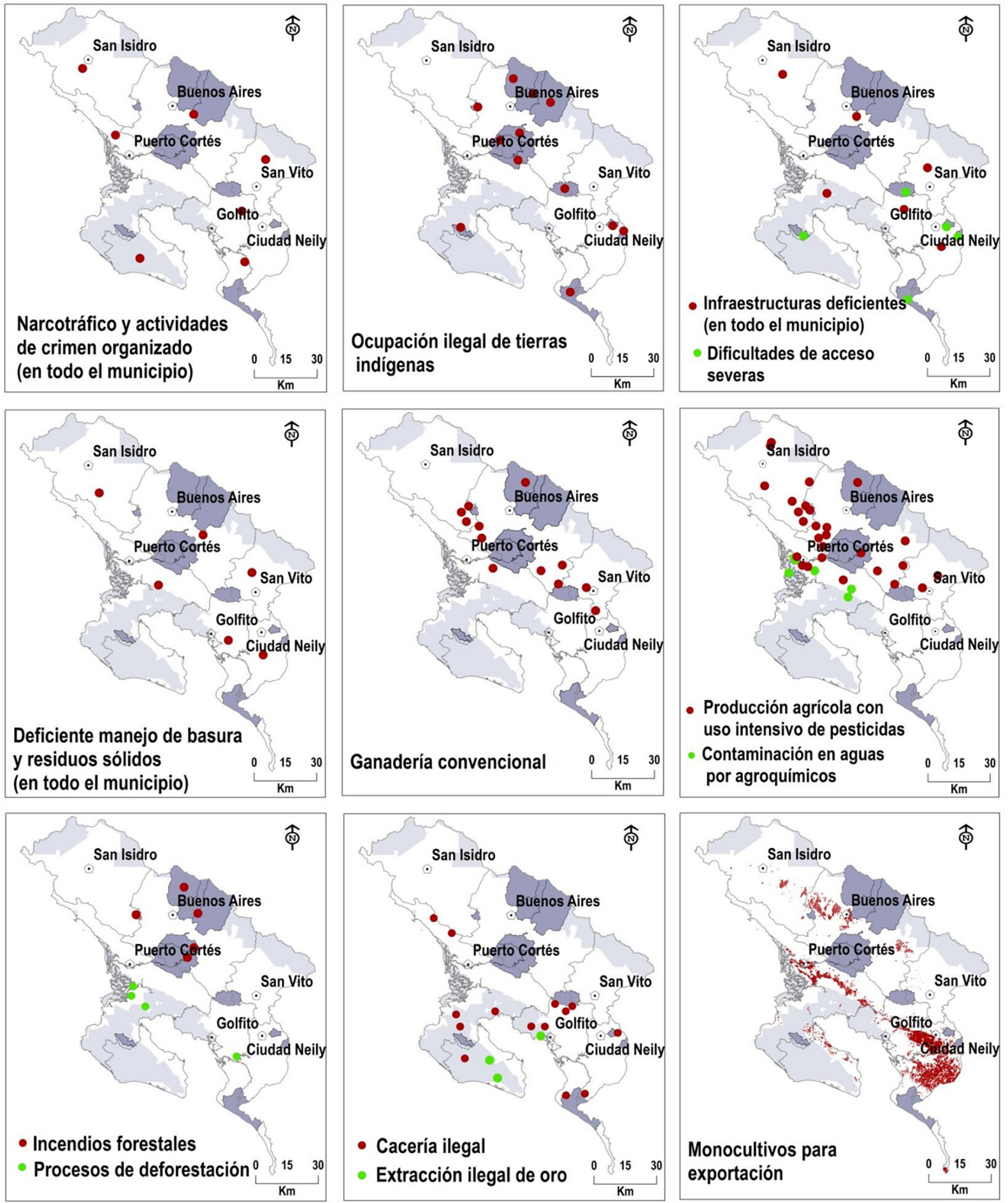

Fuente: Bases cartográficas del Atlas del Instituto Tecnológico de Costa Rica (2014) y del PRIAS (2019a; 2019b); (Tabla 4: Ac1, Aap1, Gap1, Ta1, Ta2, Oc2, Lc1, Lc4, Lc5, Lci1, Lci2, Lci3); Comprobación de campo (2020). Elaboración propia

\section{Discusión}

La región Sur se encuentra sometida al impacto de conflictos socioambientales de alta complejidad, en un territorio que manifiesta grandes desigualdades y rezago socioeconómico, produciéndose en los últimos decenios una transformación de la estructura productiva que ha pasado de la agricultura familiar 
a la agroindustria de los monocultivos, favorecida por las políticas estatales (Rodríguez et al., 2018), y a partir de la tendencia de la región Centroamericana (Gómez, 2018). En una escala más amplia, la presión sobre la agricultura familiar se enmarca en el contexto de subordinación de los sistemas agroalimentarios nacionales de América Latina y el Caribe a los patrones de consumo de los países centrales (Segrelles, 2001). Esto a su vez ha conllevado el cambio en la estructura social de la región, e inclusive de los patrones culturales, al evidenciarse el abandono de los sistemas productivos tradicionales indígenas (Arroyo y León, 2017; León et al., 2019).

Las políticas neoliberales han impulsado la producción animal intensiva basada en piensos importados de bajo coste, cultivos como la piña y la palma aceitera altamente dependientes de insumos químicos de elevado costo, excluyendo así a los pequeños agricultores (Tabla 4: Pag2, Lc2, Agp1, Lci4). Estos cultivos, de acuerdo a los actores entrevistados (Tabla 4: Lc1, Lc2, Lc3, Lc4, Lc5, Lcil, Lci4), acaparan la mano de obra local, lo que provoca que se abandonen las parcelas agrícolas de autoconsumo. Mientras que cultivos como el maíz y los frijoles — de bajos insumos externos- llevados a cabo por pequeños productores han sido desfavorecidos (Galt, 2020). De esta forma se ha reducido el número de productores de granos básicos en todo el país y en general en el Istmo a partir de los años noventa (Baumeister, 2019). Este sistema productivo conlleva una homogeneización de la economía rural (Shaver et al., 2015) y una modificación del mapa de actores de los sistemas agroalimentarios, donde se favorece el capital concentrado en detrimento de la agricultura familiar (Rodríguez et al., 2018). Finalmente, la externalización de los impactos ecológicos y sociales de este sistema productivo son sufridos por las clases trabajadoras, los ecosistemas y las especies (Galt, 2020).

Si bien, los modelos y estrategias de desarrollo y de producción han cambiado su planteamiento a lo largo del tiempo, se evidencia como, la tendencia a centrar la economía en unos pocos productos de exportación, sujetos a los vaivenes del mercado, ha ocasionado problemas reiterativos (Picado y Botella, 2017). Tal es el antecedente de la expansión cafetalera, cuando ya a mitad del siglo XIX se registraron importaciones de arroz, frijoles, maíz, trigo y carne, debido al desplazamiento de estos recursos alimentarios básicos de la producción nacional (León, 2012), además del caso de la expansión ganadera en los años sesenta y setenta (Bozzoli de Wille, 1977; Kaimowitz, 1996).

Para Amador et al. (2011), la estructura y la dinámica productiva actual de la región, con sus grandes contrastes, es producto de los Programas de Ajuste Estructural implementados durante la década de los ochenta, que limitaron el desarrollo de actividades productivas de pequeña y mediana escala asociadas a la producción de granos y de hortalizas, en tanto que propiciaron el asentamiento y consolidación de grandes áreas de producción de monocultivos (piña, palma y, en menor medida, arroz), en manos de pocos productores o, en el mejor de los casos, dependientes de procesos de industrialización. Más que un modelo de desarrollo, como señala Vargas (2015) se trata de un "proyecto histórico neoliberal" que englobaría tanto lo político (relaciones de poder internas y externas), como lo económico (organización de los mercados y sectores de acumulación de capital, así como los aspectos ideológicos (visión de mundo coincidente con las estructuras de poder) e inclusive culturales, ya que como resultado se manifiestan formas de vida particulares que se articularían con las estructuras económicas y las político-ideológicas imperantes. Este proyecto explicaría estas estructuras, así como su evolución dinámica en el período de 1984-2015 en Costa Rica, cuando se gesta la "economía hacia afuera" (centrífuga).

En este contexto, es manifiesto el impulso del Estado a la agroindustria de monocultivos (Gómez, 2018; Maglianesi-Sandoz, 2013; Rodríguez et al., 2018), de tipo empresarial y más rentable, mientras que se acentúa la vulnerabilidad de la agricultura familiar y del sistema productivo indígena, siendo elementos que ayudan a conservar diferentes tipos de patrimonio: paisajístico, rural, cultural, agrobiológico y natural; así como la seguridad social y alimentaria de los habitantes locales (Gómez, 2018; León et al., 2019).

Los escasos recursos destinados a la conservación de la biodiversidad impiden una adecuada gestión de los espacios protegidos (Tabla 4: Lc1, Ta1, Oc1, Pg1, Pg2), lo cual aumenta su vulnerabilidad ante diversas presiones antrópicas relacionadas con la producción agraria insostenible (grandes extensiones de monocultivos y ganadería convencional); ilícitos ambientales (deforestación, cacería y minería ilegales); deficiente manejo de residuos y contaminación; así como el narcotráfico y la narcoproducción. Estos fenómenos se insertan dentro de las comunidades rurales y los ENP dando origen a intensas transformaciones en el paisaje y en la estructura social y económica (Bonatti et al., 2005; Wrathall et al., 2020).

Aguilar-González, Cerdán, Kocian y Aguilar-Umaña (2017) hablan de un fenómeno que denominan narco-deforestación, actividad que se manifiesta de formas diversas, incluyendo la compra de tierras, 
adyacentes o dentro de las áreas protegidas, para el desarrollo de diversas actividades productivas y para el establecimiento de rutas de transporte; generando profundas alteraciones en las dinámicas de desarrollo rural, al infiltrarse dentro de los sistemas de comercio locales mediante la generación de latifundios para ganadería extensiva, la adquisición de sistemas de producción y comercio, entre otros. Se trata de territorios denominados como "tierra de nadie", donde la escasa acción estatal los convierte en tierra fértil para la criminalidad (Foucher, 1991).

La falta de conectividad con el principal centro de desarrollo del país (el Valle Central), contribuye además a la sensación general de abandono que expresan usualmente los habitantes de territorios rurales o indígenas respecto del Estado (Tabla 4: Lc1, Lc2, Lc5, Pag2, Pg1, Agpi, Lcil, Clg1). No solamente es importante la accesibilidad de un territorio sino también la facilidad con la que los habitantes y la producción tienen para salir de éste y conectarse con el resto del territorio (Sieber, 1997). Pese a que el Îndice de Acceso Rural (RAI) en Costa Rica es cercano al 80\%, la red pavimentada supone solamente el $27 \%$, siendo los caminos rurales (vías terciarias) un $70 \%$ del total de la red vial del país (Pérez, 2020). Por tanto, las áreas más alejadas, como el Pacífico Sur, requieren inversión estatal para mantener y mejorar la infraestructura vial, siendo este aspecto un elemento fundamental para el desarrollo rural y la forma de favorecer la comercialización y distribución de los productos obtenidos en una agricultura familiar coherente con los Objetivos de Desarrollo Sostenible que plantea la UNESCO.

La centralización del aparato estatal y de los procesos de decisión es otro desafío que debe superar la región, lo mismo que la debilidad estructural de los gobiernos territoriales y locales para atender las demandas de la población de los territorios rurales. Esta situación refleja el patrón centro-periferia, donde los municipios más pobres del país se encuentran subordinados al centro neurálgico, como ocurre con la región Sur, situada a 6 horas 30 minutos de distancia desde la capital (Pérez, 2020).

En definitiva, la región Pacífico Sur, como otros territorios rurales del país, evidencia una serie de dinámicas y procesos territoriales que dan cuenta del modelo de desarrollo endógeno imperante desde los años ochenta y de la carencia de políticas rurales y agrarias que propicien un verdadero desarrollo rural con enfoque territorial (Mora-Alfaro, 2005). Estas dinámicas y procesos se concretan en un modelo de territorio poco integrado con el resto del país, con limitada presencia y actuación estatal, donde las fuerzas del capital trasnacional y la complicidad del Estado han promovido un modelo de desarrollo que perpetúa la pobreza y la acumulación de capital a partir del deterioro socioambiental (Harvey et al., 2004). En la Figura 5 se presentan los rasgos más evidentes del territorio de la región Pacífico Sur, tanto aquellos que representan deficiencias, como los que constituyen recursos valiosos para superar los desequilibrios.

Figura 5. Síntesis de las dinámicas territoriales en la región Pacífico Sur

\section{PACÍFICO SUR DE COSTA RICA REGIÓN PERIFÉRICA, TRANSFRONTERIZA Y DESCONECTADA DEL RESTO DEL TERRITORIO COSTARRICENSE}

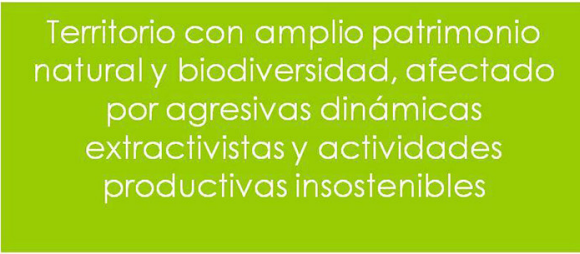

Estructura económica altamente dependiente de la agroindustria transnacional, con deterioro de sistemas agroproductivos

tradicionales y potencial para la diversificación productiva endógena

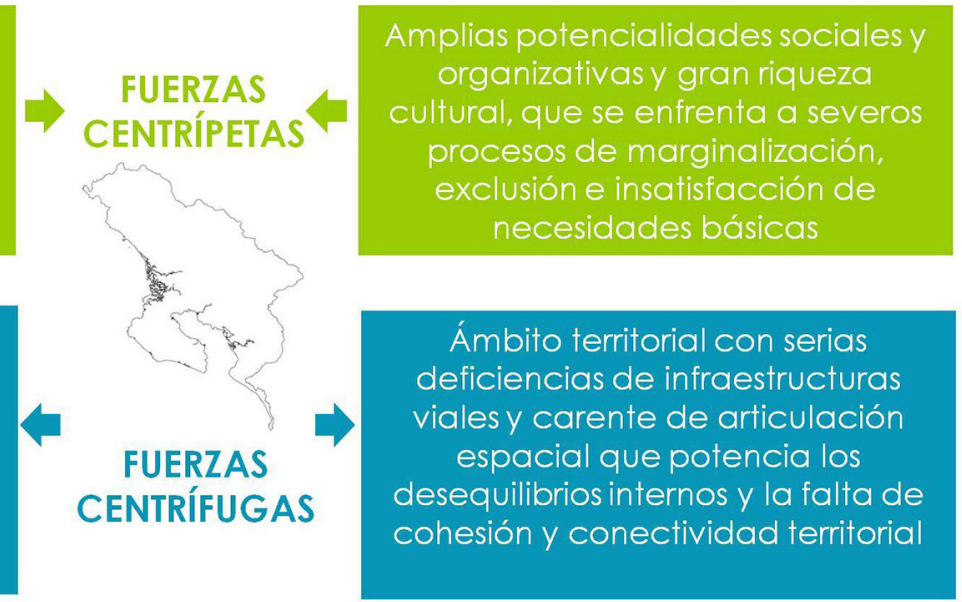

Elaboración propia 


\section{Conclusiones}

El caso de la región del Pacífico Sur, dadas sus características de región periférica en un ámbito nacional, es de enorme interés para comprender la realidad Centroamericana. Se trata de territorios que han pasado de ser invisibilizados dentro de las economías nacionales a incorporarse a la economía global a través de rápidas transformaciones del sector agroganadero, como es la producción de carne bovina para exportación y el actual auge de los monocultivos, particularmente la piña en Costa Rica. El rol de estos territorios se ha orientado a la satisfacción de demandas de consumo de Estados Unidos, pero también de la Unión Europea. En ese sentido, resulta necesario profundizar en el futuro acerca del papel de la periferia estudiada en las dinámicas económicas globales.

La situación periférica del Pacífico Sur en Costa Rica y la falta de una política de desarrollo rural, específica y a largo plazo, son cuestiones clave en la búsqueda de un modelo de territorio ambiental y socialmente más sostenible y más equilibrado. Es necesaria la inversión estatal en el mantenimiento y mejora de la infraestructura vial en esta región para el desarrollo rural y el fomento de la distribución y comercialización de la producción local. Además, para compensar los efectos sociales, económicos y ambientales de la estructura económica imperante, altamente dependiente de la agroindustria transnacional, debería potenciarse una transición hacia una agricultura que sea capaz de conservar la biodiversidad y el patrimonio natural y cultural de los territorios periféricos que, según propone Vermunt, Negro, Van Laerhoven, Verweij y Hekkert (2020), permita la transformación del sector agroalimentario hacia un modelo más sostenible, con un ajuste específico a las condiciones socio ecológicas y al interés en la innovación.

Según este contexto, parece que el modelo económico imperante se sirve de un aprovechamiento sistemático de la pobreza local para fortalecer las actividades de tipo extractivista, en detrimento de las actividades y emprendimientos agroproductivos de la agricultura familiar, de lo cual también saca partido el narcotráfico para sus actividades ilícitas. A pesar de ello, se manifiestan las capacidades locales y se fortalecen los modelos de gobernanza que apuestan por el desarrollo socioeconómico enfocado en la conservación, particularmente en las comunidades aledañas a las áreas protegidas. Dicha agricultura familiar, en el contexto Centroamericano, tiene un rol estratégico en el desarrollo rural, debido a su incidencia en los procesos productivos y comerciales, así como para la erradicación de la pobreza y la adaptación al cambio climático (Gómez, 2018). Es imprescindible el desarrollo de políticas rurales que apoyen las explotaciones de agricultura familiar, los pequeños y medianos emprendimientos productivos y el turismo rural como modelos de negocio basados en el uso sostenible de la biodiversidad, como estrategia de conservación del capital natural y social de la región.

\section{Referencias}

Abarca, A. y Ramírez, S. (2016). Estudio Del Crecimiento Económico Costarricense, 1960-2014. Recuperado de https://www.odd.ucr.ac.cr/sites/default/files/Documents/Crecimiento-Economico/Estudio-delCrecimiento-Economico.pdf

Aguilar-González, B., Cerdán, P., Kocian, M. y Aguilar-Umaña, A. (2017). Impactos de la Narcodeforestación sobre las Áreas Protegidas en Centroamérica: Una Aproximación desde la Economía Ecológica Crítica. En: Alonso, A., Moreno, D., y Camps, S. (Eds.), Perspectivas de la economía ecológica en el nuevo siglo (pp. 241-270). México: Universidad de Guadalajara Press.

Algeet-Abarquero, N., Marchamalo, M., Bonatti, J., Fernández-Moya, J. y Moussa, R. (2015). Implications of land use change on runoff generation at the plot scale in the humid tropics of Costa Rica. Catena, 135, 263-270. https://doi.org/10.1016/j.catena.2015.08.004

Amador, M., Sánchez, J., Arguedas, M., Araya, R., Guevara, F, Maroto, D., ... Vargas, F. (2011). Informe Final de Investigación Estudio Regional sobre el Desarrollo Local de los Cantones (Trans) Fronterizos del Pacífico Sur de Costa Rica. San José, Costa Rica: IFCMDL, Universidad Estatal a Distancia. Recuperado de https://www.uned.ac.cr/extension/images/ifcmdl/CONTENIDO1.pdf

Arce, L. E. (2014). San Isidro de El General en el tiempo. San José, Costa Rica: El Atabal.

Arias, R. y Muñoz, J. (2007). Reforma Económica y Modelo de Promoción de Exportaciones: logros y vacíos de la política de desarrollo de las últimas dos décadas. Revista de Ciencias económicas, 25(1), $15-40$. 
Arroyo, N. y León, J. (2017). Cambios en la estructura productiva del sector rural costarricense con base en el Censo Agropecuario 2014. En INEC (Ed.). En Una visión del sector agropecuario basada en el CENAGRO 2014 (pp. 91-134). San José, Costa Rica: INEC.

Bartels, J. y Araya, A. (Julio de 2010). El Desarrollo de la Agricultura en la Región Pacífico Sur de Costa Rica (1909-1955). X Congreso Centroamericano de Historia. Congreso llevado a cabo en el Recinto Universitario Rubén Darío "Rubén Darío", UNAN-Managua, Nicaragua.

Baumeister, E. (2019). Estructuras Agrarias de América Central: Continuidades y Cambios. Revista latinoamericana de Estudios Rurales, 4(7), 259-284. Recuperado de http://www.ceil-conicet.gov.ar/ojs/ index.php/revistaalasru/article/view/566/403

Bonatti, J., Borge, C., Herrera, B. y Paaby, P. (2005). Efectos ecológicos del cultivo de la piña en la cuenca media del Río General-Térraba de Costa Rica. (Informe Técnico N. ${ }^{4}$ ). San José, Costa Rica: SEDER. Recuperado de http://pnp.cr/es/efectos-ecologicos-del-cultivo-de-la-pina-en-la-cuenca-media-delrio-general-terraba-de-costa-rica

Bonilla, E. (2008). Realidad de las Comunidades Rurales de Costa Rica. Revista Electrónica Educare, 12 , 47-59. https://doi.org/10.15359/ree.12-Ext.5

Botella, E. (2010). El modelo agrario costarricense en el contexto de la globalización (1990-2008): oportunidades y desafíos para reducir la pobreza. Documentos de Trabajo (Centro de Estudios sobre la Despoblación y Desarrollo de Áreas Rurales), 1, 1-42.

Bozzolli de Wille, M. (1977). La frontera agrícola de Costa Rica y su relación con el problema agrario en zonas indígenas. Anuario de Estudios Centroamericanos, 3, 225-234

Calvo, J. (2012). Competitividad Brunca: La Región Brunca avanza hacia un desarrollo sostenible y participativo. Recuperado de https://www.sdgfund.org/sites/default/files/PS_CASO\%20DE\%20 ESTUDIO_CRica_Modelo\%20de\%20Competitividad\%20Region\%20Brunca.pdf

CANAPEP. (s.f.). Estadísticas. Recuperado de https://canapep.com/estadisticas/

Carazo, E. y Aravena, J. (2016). Condiciones de Producción, Impactos Humanos y Ambientales en el Sector Piña en Costa Rica. San José, Costa Rica: Oxfam Alemania. Recuperado de https://www.oxfam.de/ system/files/condiciones_laborales_y_ambientales_de_la_pina_en_costa_rica_-_mayo_2016.pdf

Carmack, R. M. (1994). Soplos de viento en Buenos Aires. San José, Costa Rica: Editorial de la Universidad de Costa Rica.

Castillo, O. (2006). Apertura Económica, políticas agrícolas y campesinado entre tres sistemas agrarios de la Región Huetar Norte, Costa Rica (Tesis de maestría). Universidad de Costa Rica, San José, Costa Rica.

Central America Data. (15 de Julio de 2019). Cultivos en Centroamérica: Principales cifras en 2018. Recuperado de https://www.centralamericadata.com/es/article/home/Cultivos_Principales_cifras_ en_2018

Central America Data. (10 de febrero del 2020). Aceite de palma: Más negocios con México. Recuperado de https://www.centralamericadata.com/es/article/home/Aceite_de_palma_Ms_negocios_con_Mxico

Centro Centroamericano de Población (CCP). (2011). Base de datos Censos de Población y Vivienda 2011. Recuperado de http://consultas.ccp.ucr.ac.cr

Centro de Investigación en Cultura y Desarrollo (CICDE). (2014). Informe de Investigación: La lucha por la cedulación del pueblo ngäbe en Costa Rica Alcances y significados político- culturales en la década del noventa. Recuperado de http://biblioteca.clacso.edu.ar/Costa_Rica/cicde-uned/20170703023937/ pdf_860.pdf

CEPAL, FAO, IICA. (2013). Perspectivas de la agricultura y del desarrollo rural en las Américas: una mirada hacia América Latina y el Caribe, 2014. San José, Costa Rica: IICA. Recuperado de https://repositorio. cepal.org/bitstream/handle/11362/37136/1/Perspectivas_agricultura2014_es.pdf

Comisión Económica para América Latina y el Caribe [CEPAL]. (2019). Perspectivas de la agricultura y del desarrollo rural en las Américas: una mirada hacia América Latina y el Caribe 2019-2020. San José, Costa Rica: IICA. Recuperado de https://bit.ly/36TPNO5

Comité Sectorial Regional Agropecuario (CSRA). (2007). Plan Sectorial Agropecuario 2007-2010. Recuperado de http://www.infoagro.go.cr/InfoRegiones/Documents/PRDA_2007-2010_Brunca.pdf 
Consejo Agropecuario Centroamericano (CAC). (2010). Estrategia Centroamericana de Desarrollo Rural Territorial 2010-2030 •ECADERT•. San José, Costa Rica: SICA. Recuperado de https://www.sica.int/ documentos/estrategia-centroamericana-de-desarrollo-rural-territorial-ecadert_1_80566.html

Corrales, L. (2019). Uso, conservación y gestión de la biodiversidad y los recursos forestales. Programa Estado de la Nación (ed.). Informe Estado de la Nación 2019. Recuperado de https://www. researchgate.net/profile/Lenin_Corrales/publication/337273092_Uso_conservacion_y_gestion_de_ la_biodiversidad_y_los_recursos_forestales/links/5dce1343299bf1b74b425ee9/Uso-conservacion-ygestion-de-la-biodiversidad-y-los-recursos-forestales.pdf

De Camino, R., Villalobos, R. y Morales, J.P. (2015). Costa Rica Case Study: Prepared for FAO as part of the State of the World's Forests 2016 (SOFO). Costa Rica: FAO. Recuperado de http://www.fao.org/3/aC0180e.pdf

Durango, S., Sierra, L., Quintero, M., Sachet, E., Paz, P., Da Silva, M., ... y Le Coq, J.F. (2019). Estado y perspectivas de los recursos naturales y los ecosistemas en América Latina y el Caribe (ALC). 2030 Alimentación, agricultura y desarrollo rural en América Latina y el Caribe, No. 9. Santiago de Chile: FAO.

Echeverría-Sáenz, S., Mena, F., Pinnock, M., Ruepert, C., Solano, K., de la Cruz, E.,... y Barata, C. (2012). Environmental hazards of pesticides from pineapple crop production in the Río Jiménez watershed (Caribbean Coast, Costa Rica). Science of the Total Environment, 440, 106-114. https://doi.org/10.1016/j. scitotenv.2012.07.092

Fernández Arias, M. E. (2003). La agricultura costarricense ante la globalización: Las nuevas reglas del comercio internacional y su impacto en el agro. San José, Costa Rica: Editorial Universidad de Costa Rica. Recuperado de http://bibliotecavirtual.clacso.org.ar/Costa_Rica/iis-ucr/20120725045133/ agricultura.pdf

Foucher, M. (1991). Fronts et Frontières: Un Tour Du Monde Géopolitique. Francia: Fayard

Galt, R. (2020). The Costa Rican Agrifood System, 1961-2014: Assessing Neoliberalism's Impacts on Agriculture and Diets. In Fletcher, R., Dowd-Uribe, B., Aistara, G. (eds) The Ecolaboratory: Environmental Governance and Economic Development in Costa Rica (pp. 25-57). https://doi. org/10.2307/j.ctvxw3pvp.4

GFA Consulting Group S. A. (2010). Informe final: Estudio del estado de la producción sostenible y propuesta de mecanismos permanentes para el fomento de la producción sostenible. Recuperado de http://www.mag. go.cr/bibliotecavirtual/P01-0851.pdf

Gómez, I. (2018). Centroamérica: la agricultura familiar en el desarrollo territorial. Revista Estudios Sociales, 83, 1-26.

Gómez, I., Le Coq, J.F. y Samper, M. (2014). Las agriculturas familiares en Centroamérica: Procesos y perspectivas. San Salvador, El Salvador: Prisma. Recuperado de https://agritrop.cirad.fr/573728/1/ Gomez\%20et\%20al\%20-\%202014\%20-\%20las\%20agriculturas_familiares_en_centroamerica procesos_y_perspectivas.pdf

González, H. (18 al 22 de octubre de 1993). Desarrollo polarizado y perspectivas de la agricultura nacional. La Agricultura de hoy, para la Costa Rica del mañana. IX Congreso Nacional Agropecuario y de Recursos Naturales llevado a cabo en el Colegio de Ingenieros Agrónomos. San José, Costa Rica

Hall, C. (1976). El café y el desarrollo histórico-geográfico de Costa Rica. San José, Costa Rica: Editorial de la Universidad de Costa Rica.

Harvey, C., Alpízar, F., Chacón, M. y Madrigal, R. (2004). Assessing linkages between agriculture and biodiversity in Central America: Historical overview and future perspectives. Mesoamerican y Caribbean Region, Conservation Science Program San José, Costa Rica: The Nature Conservancy

Instituto Costarricense del Café (ICAFE). (2019). Informe sobre la actividad cafetalera de Costa Rica. Heredia, Costa Rica: Instituto Costarricense del Café. Recuperado de http://www.icafe.cr/wp-content/ uploads/informacion_mercado/informes_actividad/actual/Informe\%20Actividad\%20Cafetalera.pdf

Instituto de Desarrollo Rural (INDER). (2014). Informe de Caracterización del Territorio Buenos Aires-Coto Brus. Recuperado de https://www.inder.go.cr/buenos-aires-coto-brus/Caracterizacion-BuenosAiresCotoBrus.pdf 
Instituto Nacional de Estadística y Censos (INEC). (2011). Población total en territorios indígenas por auto identificación a la etnia indígena y sexo, según pueblo y territorio indígena. Recuperado https://www.inec. cr/documento/censo-2011-poblacion-total-en-territorios-indigenas-por-autoidentificacion-la-etnia

Instituto Nacional de Estadística y Censos (INEC). (2012). Encuesta Nacional de Hogares Julio 2012: Resultados Generales. San José, Costa Rica: INEC. Recuperado de https://www.inec.cr/sites/default/ files/documentos/empleo/publicaciones/reenaho2012-01.pdf

Instituto Nacional de Estadística y Censos (INEC). (2018). Costa Rica en Cifras: 2018. Recuperado de https://www.inec.cr/sites/default/files/documetos-biblioteca-virtual/recostaricaencifras2018.pdf

International Union for Conservation of Nature (IUCN). (2017). Mexico, Central America and the Caribbean National Regional Office Anual Report 2017. Recuperado de https://portals.iucn.org/library/ sites/library/files/documents/2018-010-En.pdf

Kaimowitz, D. (1996). Livestock and Deforestation Central America in the 1980s and 1990s: A Policy Perspective. Jakarta: Indonesia: Center for International Forestry Research.

Lawrence, F. (2 de Octubre de 2010). Bitter fruit: the truth about supermarket pineapple. The Guardian. Recuperado de https://bit.ly/2IMa5kJ

Leiva, C. y Vargas, J. (2017). La productividad, el uso de tecnologías en los productos agrícolas y tendencias futuras. En INEC (ed.). En Una visión del sector agropecuario basada en el CENAGRO 2014 (pp. 67-90). San José, Costa Rica: INEC.

León, J. (2012). Historia económica de Costa Rica en el siglo XX: Vol. II. San José, Costa Rica: Editorial Universidad de Costa Rica.

León, Y., González, F. y López, N. (2019). Impacto de la producción piñera en la población de la zona de amortiguamiento de la Reserva de Biosfera La Amistad, Costa Rica. Revista Agroecológica LEISA, 34(4), 29-31. Recuperado de http://www.leisa-al.org/web/images/stories/revistapdf/vol34n4.pdf

Maglianesi-Sandoz, M. (2013). Desarrollo de las piñeras en Costa Rica y sus impactos sobre ecosistemas naturales y agro-urbanos. Biocenosis, 24 (1-2), 62-70.

Medina, L. (2004). Le Dilemme Des Frontières En Amérique Centrale: Marges Symboliques Ou Espaces En Construction : Le Cas Des Frontières Nicaragua-Costa Rica et Costa Rica-Panamá (Tesis doctoral). Université de Paris-Nanterre, France.

Méndez, R. (2016). Con Hacha y Machete. Heredia, Costa Rica: Imprenta Morales.

Ministerio de Agricultura y Ganadería (MAG). (2007). Plan Estratégico de la Cadena Productiva Palma aceitera. Recuperado de http://www.mag.go.cr/bibliotecavirtual/E70-4277.pdf

Ministerio de Planificación Nacional y Política Económica (MIDEPLAN). (2014). Región Brunca: Plan de Desarrollo 2030. Recuperado de https://documentos.mideplan.go.cr/share/s/ ZSbIneE2TOK8aq0CDaiuHw

Molina, I. (2005). Del Legado Colonial Al Modelo Agroexportador. San José: Editorial de la Universidad de Costa Rica.

Mora-Alfaro, J. (2005). Política agraria y desarrollo rural en Costa Rica: elementos para su definición en el nuevo entorno internacional. Agronomía costarricense, 29(1), 101-133

Morales Gamboa, A., Acuña González, G., Andrade-Eekhoff, K., Barrantes, A., Cuéllar, N., Herradora, ... y Zúñiga Céspedes, H. (2011). Migración de relevo: Territorios locales e integración regional en Centroamérica. San José, Costa Rica: FLACSO.

Myers, N., Mittermeier, R. A., Mittermeier, C. G., Da Fonseca, G. A. y Kent, J. (2000). Biodiversity hotspots for conservation priorities. Nature, 403(6772), 853-858. https://doi.org/10.1016/j. scitotenv.2012.07.092

OECD/FAO. (2019). OECD-FAO Agricultural Outlook 2019-2028. Paris, Francia: OECD publishing / Roma, Italia: FAO. https://doi.org/10.1787/19991142

Ortiz-Malavasi, E. (2014). Atlas de Costa Rica 2014. Cartago, Costa Rica: Instituto Tecnológico de Costa Rica. 
Pérez, G. (2020). Caminos rurales: vías claves para la producción, la conectividad y el desarrollo territorial. (Boletín $N^{\circ}$ 377). Facilitación, comercio y Logística en América latina y el Caribe. Recuperado de https://repositorio.cepal.org/bitstream/handle/11362/45781/1/S2000418_es.pdf

Picado, W. y Botella, E. (6 - 9 de septiembre de 2017). Tenencia de la tierra y cambio territorial en Costa Rica (1950-2015). XII Congreso Internacional de la Asociación Española de Historia Económica. Congreso llevado a cabo en Salamanca, España.

Programa de Investigaciones Aerotransportadas y Sensores Remotos e in situ (PRIAS). (2019a). Capas del proyecto Monitoreo de Cambio en Paisajes Productivos, con información sobre el área del paisaje productivo de piña en Costa Rica. Recuperado de https://www.snitcr.go.cr/ico_servicios_ogc_ info?k=bm9kbzo6MTY=\&nombre=MONITOREO\%20PI\%C3\%91A

Programa de Investigaciones Aerotransportadas y Sensores Remotos e in situ (PRIAS). (2019b). Capas del proyecto Monitoreo de Cambio en Paisajes Productivos, con información sobre el área del paisaje productivo de palma aceitera en Costa Rica. Recuperado de https://www.snitcr.go.cr/ico_servicios_ogc_ info?k=bm9kbzo6NTY=\&nombre=MONITOREO\%20PALMA

Quesada, O. (2007). Política agrícola centroamericana, 2008-2017: Una agricultura competitiva e integrada para un mundo global. San José, Costa Rica: Consejo Agropecuario Centroamericano.

Rodríguez, T. (2014). Gouverner Lenvironnement Dans Des Régions Frontalières. Coopération et Conflits Dans Les Bassins Du Fleuve San Juan (Costa Rica-Nicaragua) et Du Flueve Sixaola (Costa Rica-Panama) (Tesis doctoral). Universidad de Paris VII-Paris Diderot, Paris, Francia.

Rodríguez, T., Obando, A. y Acuña, M. (2018). Entender el extractivismo en regiones fronterizas. Monocultivos y despojo en las fronteras de Costa Rica. Sociedad y Ambiente, 17, 165-200.

Saénz, F. (2002). Política agrícola en Costa Rica y su efecto sobre el campesinado. ¿Tendrá la educación "alguna vela en este entierro"?. Revista Electronica Educare, 3, 87-101. https://doi.org/10.15359/ ree.2002-3.7

Salido, J. (2015). Una mirada a los países del Proyecto Mesoamérica. Documento elaborado para la XV Cumbre del Mecanismo de Diálogo y Concertación de Tuxtla Ciudad de Guatemala, Guatemala. Viernes 26 de junio de 2015 (LC/MEX/L.1183). México, D.F.: Naciones Unidas. recuperado de https:// repositorio.cepal.org/bitstream/handle/11362/38426/S1500579_es.pdf

Sánchez-Azofeifa, A. (2015). Análisis de la cobertura forestal de Costa Rica entre 1960 y 2013. Ambientico, 253, 4-11. Recuperado de http://www.ambientico.una.ac.cr/pdfs/ambientico/253.pdf

Sánchez-Azofeifa, A., Foley, S., Calvo, J., Arroyo, P., Hamilton, S. y Jiménez, V. (2002). Estudio de cambios de Cobertura Forestal de Costa Rica 1997-2000. San José, Costa Rica: Alberta University, Edmonton y Centro Científico Tropical.

Sandner, G. (1961). Aspectos geográficos de la colonización agrícola en el Valle del General. San José, Costa Rica: Instituto Geográfico Nacional

Schneider, S. (2016). Family farming in Latin America and the Caribbean: looking for new paths of rural development and food security. International Policy Centre for Inclusive Growth (IPC-IG) Working Paper No. 137. Brasil: FAO.

Segrelles, J.A. (2001). Problemas ambientales, agricultura y globalización en América Latina. Scripta Nova. Revista electrónica de Geografía y Ciencias Sociales, 5(92), 32.

Shaver, I., Chain-Guadarrama, A., Cleary, K., Sanfiorenzo, A., Santiago-García, R., Waits, L., ... y Fagan, M. (2015). Coupled Social, Economic and Ecological Outcomes of Agricultural Intensification in Costa Rica and the Future of Biodiversity Conservation in Tropical Agricultural Regions. Journal of Global Environmental Change, 32, 74-86. https://doi.org/10.1016/j.gloenvcha.2015.02.006

Sieber, N. (1997). An Annotated Bibliography on Rural Transport. https://doi.org/10.3362/9781780444505 Sistema Nacional de Áreas de Conservación (SINAC). (s.f.). Área de Conservación La Amistad-Pacífico (ACLAP). Recuperado de http://www.sinac.go.cr/ES/ac/aclap/Paginas/default.aspx

Sistema Nacional de Áreas de Conservación (SINAC). (2012). Plan de Manejo: Parque Internacional La Amistad-Talamanca. San José, Costa Rica: MINAET, SINAC. Recuperado de http://www.sinac.go.cr/ ES/planmanejo/Plan\%20Manejo\%20ACLAC/Parque\%20Internacional\%20La\%20Amistad.pdf 
Solórzano, J.C. (1992). Conquista, colonización y resistencia indígena en Costa Rica. Revista de Historia, 25, 191-205.

Ulate, A., Mayorga, B. y Alfaro, J. (2017). Índice de Competitividad Cantonal 2006-2017. San José, Costa Rica: Escuela de Economía y el Observatorio del Desarrollo (ODD)de la Universidad de Costa Rica. Recuperado de https://odd.ucr.ac.cr/sites/default/files/icc-2006-2016/icc-2006-2016.pdf

Valverde, M., Rodríguez, G. y Mora, E. (2018). Informe de gestión del Sector Agropecuario y Rural mayo 2014-Abril 2018 (No. D10/10967). San José, Costa Rica: Secretaría Ejecutiva de Planificación Sectorial Agropecuaria (SEPSA). Recuperado de http://www.mag.go.cr/bibliotecavirtual/D10-10967.pdf

Van den Hombergh, H. (1999). Guerreros del Golfo Dulce: industria forestal y conflicto en la Península de Osa, Costa Rica. https://doi.org/10.5962/bhl.title.124155

Vargas, D. y Mora, S. (2017). Propuesta de tipificación de la agricultura familiar en los cantones de Coto Brus, Golfito y Buenos Aires, de Puntarenas, Costa Rica. En INEC (ed.). En Una visión del sector agropecuario basada en el CENAGRO 2014 (pp. 545-566). San José, Costa Rica: INEC.

Vargas, L. (2015). Modelo desarrollista y de industrialización sustitutiva. San José, Costa Rica: Editorial de la Universidad de Costa Rica.

Vermunt, D. A., Negro, S. O., Van Laerhoven, F. S. J., Verweij, P. A. y Hekkert, M. P. (2020). Sustainability transitions in the agri-food sector: How ecology affects transition dynamics. Environmental Innovation and Societal Transitions, 36, 236-249. https://doi.org/10.1016/j.eist.2020.06.003

Wrathall, D. J., Devine, J., Aguilar-González, B., Benessaiah, K., Tellman, E., Sesnie, S., ...\& Dávila, A. (2020). The impacts of cocaine-trafficking on conservation governance in Central America. Global Environmental Change, 63, 102098. https://doi.org/10.1016/j.gloenvcha.2020.102098 